\title{
Expression of thymosin $\beta 4$ in odontoblasts during mouse tooth development
}

\author{
BAIK-DONG CHOI $^{1 *}$, SEONG-HO YUN ${ }^{2 *}$, SOON-JEONG JEONG ${ }^{1}$, \\ GUANLIN WANG ${ }^{1}$, HEUNG-JOONG KIM ${ }^{2}$, DO-SEON LIM ${ }^{3}$ and MOON-JIN JEONG ${ }^{1}$ \\ Departments of ${ }^{1}$ Oral Histology and Developmental Biology and ${ }^{2}$ Oral Anatomy, \\ School of Dentistry, Chosun University, Gwangju 501-759; ${ }^{3}$ Department of Dental Hygiene, \\ Eulji University, Seongnam, Gyeonggi-do 461-713, Republic of Korea
}

Received November 29, 2011; Accepted January 16, 2012

DOI: $10.3892 / \mathrm{ijmm} .2012 .913$

\begin{abstract}
Thymosin $\beta 4$ (T $\beta 4)$ is expressed in developing tissue, where it stimulates cell differentiation and migration. Further, T $\beta 4$ is expressed during molar development in mice, but the expression and function of $\mathrm{T} \beta 4$ in odontoblasts during mammalian tooth development have not yet been reported. Therefore, this study examined the expression and function of $\mathrm{T} \beta 4$ in differentiating odontoblasts during tooth development. As observed by immunohistochemistry, $\mathrm{T} \beta 4$ was expressed in the oral epithelium and inside cells of the tooth bud on embryonic day 15 (E15). Further, on E17, T $\beta 4$ was expressed strongly in the dental lamina and oral epithelium, but only expressed in part of the cells in the outer and inner dental epithelium. $\mathrm{T} \beta 4$ was strongly expressed in the entire cytoplasm of odontoblasts on postnatal day 1 (PN1) and expressed intensively in the apical area of odontoblasts on PN4. Further, expression of T $\beta 4$ was increased gradually in odontoblasts from PN1 to PN21. In an odontoblast cell line, MDPC-23, expression of T $\beta 4$ mRNA and protein was increased strongly on day 4 and gradually decreased from day 14 . The gene expression of dentin sialophosphoprotein (DSPP), bone sialoprotein (BSP), osteocalcin $(\mathrm{OCN})$, osteonectin $(\mathrm{ON})$, and collagen type I, related with mineralization, was significantly decreased in si-T $\beta 4 /$ MDPC-23 during differentiation compared to that in MDPC-23 cells. Taken together, our results suggest that $\mathrm{T} \beta 4$ may be involved in oral epithelial cell proliferation at the initial stage of tooth development and regulates the expression and secretion of proteins during odontoblast differentiation.
\end{abstract}

Correspondence to: Professor Moon-Jin Jeong, Department of Oral Histology and Developmental Biology, School of Dentistry, Chosun University, 375 Seo-Suk Dong, Gwangju, Republic of Korea E-mail: mjjeong@chosun.ac.kr

${ }^{*}$ Contributed equally

Key words: thymosin $\beta 4$, tooth development, odontoblast differentiation

\section{Introduction}

Tooth development is divided into three sequential stages, the bud, cap, and bell stages. Among these stages, formation of dentin is initiated at the late bell stage by odontoblasts located in the periphery of the pulp (1). Odontoblasts are differentiated from dental papilla cells, and the formation and mineralization of dentin involves the secretion of organic matrix, including collagenous and noncollagenous proteins, to the adjacent inner dental epithelium (2). The dentin matrix constitutes proteins involved in the regulation of mineralization, such as dentin sialoprotein (DSP), dentin phosphoprotein (DPP), and bone sialoprotein (BSP) (3). Mineralization of dentin by odontoblasts proceeds through the secretion of membrane-bound vesicles containing collagenous and noncollagenous proteins (4). In the secretory phase, odontoblasts are elongated in length, showing polarity, and display a well-developed rough endoplasmic reticulum, and vesicles are secreted after transport toward the odontoblastic process near the dentinal tubule (5).

Thymosin $\beta 4$ (T $\beta 4$ ) is known to be a $4.9 \mathrm{kDa}$ actin-sequestering peptide that regulates cell differentiation and migration $(6,7)$. Treatment with $\mathrm{T} \beta 4$ accelerates wound-healing in mouse skin and inhibits apoptosis by inducing an increase in $\mathrm{Bcl}-2$ expression and reducing caspase activity $(8,9)$. $\mathrm{T} \beta 4$ promotes the migration and differentiation of hair follicle stem cells, stimulates endothelial cell differentiation during vessel formation. Furthermore, $T \beta 4$ has been shown to be expressed in differentiating cardiac cells, the developing brain, and the mandible of mice (10-14).

Further, it was reported that $\mathrm{T} \beta 4$ is overexpressed in highly metastatic melanoma cells (15). It has also been reported that expression of $\mathrm{T} \beta 4$ may be able to stimulate the differentiation of tooth germ during mouse molar development (16). However, the direct expression and function of $T \beta 4$ in odontoblast differentiation was not demonstrated. Based on a previous report, $\mathrm{T} \beta 4$ may be a regulating factor in dentin formation and mineralization by odontoblasts, but its expression and function have not yet been reported. Therefore, the purpose of this study was to investigate the expression and function of $\mathrm{T} \beta 4$ in dentinogenesis in odontoblasts during tooth development. 


\section{Materials and methods}

Preparation of tissues and immunohistochemistry. Embryos of ICR outbred mice were used in this study. All animal studies were approved by the 'Institutional Animal Care and Use Committees' at Chosun University, and animal care was carried out using stress pathogen-free (SPF) level systems according to the 'Guide for the Care and Use of Laboratory Animals'. Embryonic (E15, E17) and postnatal (PN1, PN4, PN7, PN10, PN14, PN21) mouse heads were fixed in 4\% paraformaldehyde, decalcified in $10 \%$ ethylenediaminetetraacetic acid (EDTA, pH 7.4) solution at $4^{\circ} \mathrm{C}$ for 4 weeks, embedded in paraffin, and cut into identical mesiodistal sections. Tissue sections were pre-incubated with $0.6 \% \mathrm{H}_{2} \mathrm{O}_{2}$ in methanol for $20 \mathrm{~min}$ at room temperature. The sections were then incubated with normal goat serum (Vector Laboratories, USA) and incubated for $16 \mathrm{~h}$ with a 1:300 dilution of anti-rabbit $\mathrm{T} \beta 4$ (Immunodiagnostik, Germany) antibody at $4^{\circ} \mathrm{C}$. After color development, the sections were counterstained with hematoxylin. Rabbit pre-immune serum was used as a negative control. The pixel value represents the expression intensity of T $\beta 4$ protein in odontoblasts and the odontoblast layer. The pixel value was quantified and calculated by AxioVision LE release 4.6 software (Carl Zeiss, Germany).

T $\beta 4$-siRNA transfection and cell differentiation. The odontoblast-like cell line, MDPC-23, was plated in $60-\mathrm{mm}$ culture dishes $\left(1 \times 10^{5}\right.$ cells) and incubated in a $\mathrm{CO}_{2}$ incubator $\left(5 \% \mathrm{CO}_{2}, 37^{\circ} \mathrm{C}\right)(17)$. The cells were then cultured in Dulbecco's modified eagle's medium (DMEM) (Gibco-BRL, USA) supplemented with $1 \%$ antibiotic-antimycotic solution (Gibco-BRL) containing 10\% fetal bovine serum (Gibco-BRL). The differentiation of MDPC-23 cells was performed after reaching $90 \%$ confluence for 28 days using complete medium supplemented with $10 \mathrm{mM} \beta$-glycerophosphate (Sigma, USA) and $50 \mu \mathrm{g} / \mathrm{ml}$ of ascorbate (Sigma). The following sequences were used for the synthetic mouse T $\beta 4$-siRNA duplexes. The forward and reverse sequences of T $\beta 4$-siRNA were 5'-CAC AUC AAA GAA UCA GAA C-3' and 5'-GUU CUG AUU CUU UGA UGU G-3' (Bioneer, Korea), respectively. The MDPC-23 cells were plated in $60-\mathrm{mm}$ culture dishes and transfected with 140 pmol of T $\beta 4$-siRNA (si-T $\beta 4 / \mathrm{MDPC}-23$ ) using WellFect-si ${ }^{\mathrm{TM}}$ (WellGene, Korea).

Alizarin red S staining. Cells were plated in 6-well plates in complete medium. After differentiation, to demonstrate calcified nodules, the cells were washed twice with PBS, fixed with $50 \%$ ethanol for $10 \mathrm{~min}$, rehydrated with $1 \mathrm{ml}$ of distilled water for $5 \mathrm{~min}$, then stained with $200 \mu \mathrm{l}$ of $1 \%$ Alizarin red S (Sigma) for $3 \mathrm{~min}$ at room temperature. After staining, the cells were washed three times with distilled water, followed by $70 \%$ ethanol. To quantify matrix mineralization, the Alizarin red S-stained cultures were incubated with $100 \mathrm{mmol}$ of cetylpyridinium chloride (Acros Organics, USA) for $1 \mathrm{~h}$ to solubilize and release calcium-bound Alizarin red into the solution. The absorbance of the released Aalizarin red S was measured at $570 \mathrm{~nm}$ using a microplate reader (BioTek Instruments, USA).

Western blotting. Total cytosolic protein was extracted using NP-40 lysis buffer (150 mM NaCl, $1 \%$ NP-40, $50 \mathrm{mM}$ Tris-Cl
(pH 7.4), $2 \mathrm{mM} \mathrm{Na}_{3} \mathrm{VO}_{4}, 2 \mathrm{mM} \mathrm{Na}_{4} \mathrm{P}_{2} \mathrm{O}_{7}, 50 \mathrm{mM} \mathrm{NaF}, 2 \mathrm{mM}$ EDTA (pH 7.4), $0.1 \mu \mathrm{g} / \mathrm{ml}$ of leupeptin, and $1 \mu \mathrm{g} / \mathrm{ml}$ of aprotinin). These lysates were incubated on ice for $30 \mathrm{~min}$ and centrifuged at $13,000 \mathrm{rpm}$ and $4^{\circ} \mathrm{C}$. After protein extraction, the concentration in $30 \mu \mathrm{g}$ was determined using a $D C$ protein assay kit (Bio-Rad Laboratories), followed by electrophoresis on a $15 \%$ SDS polyacrylamide gel. After electrophoresis, the protein was transferred to a nitrocellulose membrane and blocked with 5\% non-fat dry milk for $1 \mathrm{~h}$ at room temperature. The membrane was then blotted with a 1:6,000 dilution of anti-rabbit $\mathrm{T} \beta 4$ or a 1:2,500 dilution of anti-mouse $\beta$-actin antibody (Sigma) for $16 \mathrm{~h}$ at $4^{\circ} \mathrm{C} . \beta$-actin was used as an internal control for western blotting. After washing, the membrane was blotted with a 1:5,000-1:10,000 dilution of HRP-conjugated goat anti-rabbit or mouse-IgG (SantaCruz Biotechnology, USA) and developed using chemiluminescence film (AmershamPharmacia, UK) after being treated with ECL solution (AmershamPharmacia). The sizes of the $\mathrm{T} \beta 4$ and $\beta$-actin bands were $5 \mathrm{kDa}$, and $42 \mathrm{kDa}$, respectively. The densities of the expressed bands were measured using a Science Lab Image Gauge (Fuji Film, Japan).

Reverse transcription polymerase chain reaction. Total RNA was extracted from the cells using TRI reagent (MRC Inc, USA), and PCR reaction was carried out according to the manufacturer's instructions. The following primers were synthesized (Bioneer) for RT-PCR analysis: T $\beta 4$ forward 5'-GTC AGT AAG CTT CTC CTT CCA GCA ACC ATG TC-3' and reverse 5'-GTC AGT CTC GAG AAT GTA CAG TGC ATA TTG GC-3'; dentin sialophosphoprotein (DSPP) forward 5'-CGA CCC TTG TCC AGG A-3' and reverse 5'-CAT GGA CTC GTC ATC GAA-3'; BSP forward 5'-ACC GGC CAC GCT ACT TTC TTT AT-3' and reverse 5'-TCC TCG TCG CTT TCC TTC ACT TT-3'; osteocalcin (OCN) forward 5'-TGA GGA CCC TCT CTC TGC TC-3' and reverse 5'-GAG CTC ACA CAC CTC CCT GT-3'; osteonectin (ON) forward 5'-ATT TGA GGA CGG TGC AGA GG-3' and reverse 5'-TCT CGT CCA GCT CAC ACA CCT-3'; collagen type I (Col type I) forward 5'-ATT CGG AGC TCA AGA TGT AA-3' and reverse 5'-CAG TCA AGT CCT AGC CAA AC-3'; glyceraldehyde 3-phosphate dehydrogenase (GAPDH) forward 5'-CCA TGG AGA AGG CTG GG-3' and reverse 5'-CAA AGT TGT CAT GGA TGA CC-3'. GAPDH was used as the internal control for RT-PCR. The annealing temperature for each primer and number of cycles were as follows: for $\mathrm{T} \beta 454^{\circ} \mathrm{C}$ ( 28 cycles); for DSPP $56^{\circ} \mathrm{C}$ ( 35 cycles); for BSP $60^{\circ} \mathrm{C}\left(27\right.$ cycles); for $\mathrm{OCN} 66^{\circ} \mathrm{C}\left(27\right.$ cycles); for ON $63^{\circ} \mathrm{C}(30$ cycles); for $\mathrm{Col}$ type I $49^{\circ} \mathrm{C}$ (35 cycles); for GAPDH $56^{\circ} \mathrm{C}(30$ cycles). The products were electrophoresed on $1.5 \%$ agarose gel buffered with $0.5 \mathrm{X}$ Tris-borate-EDTA and stained with ethidium bromide after amplification. The staining bands were visualized by Gel-Doc (Bio-Rad Laboratories). These primer sets recognized only the genes of interest, as indicated by the amplification of single bands of expected sizes (184 bp for T $\beta 4$; 824 bp for DSPP; 358 bp for BSP; 221 bp for OCN; 101 bp for ON; $191 \mathrm{bp}$ for Col type I; and $199 \mathrm{bp}$ for GAPDH) according to the nucleotide sequences of T $\beta 4$ (GenBank \#X16053), DSPP (GenBank \#NM_010080), BSP (GenBank \#L20232), OCN (GenBank \#X04142), ON (GenBank \#NM_009242), Col type I (GenBank \#M60424), and GAPDH (GenBank 
\#M33197). The intensities of the bands were measured using a Science Lab Image Gauge (Fuji Film).

Statistical analysis. All experiments were performed at least in triplicate. All data were reported as the mean and standard deviation using Excel 2007 statistical software (Microsoft, USA). Significant differences $(p<0.05, p<0.005)$ were determined using the Student's t-test.

\section{Results}

Expression of T $\beta 4$ protein in odontoblasts during tooth development in mice

Bud stage. On embryonic day 15 (E15), a tooth bud was formed by intense proliferation of oral epithelial cells and was surrounded by mesenchymal cells. T $\beta 4$ was expressed in the oral epithelium, inside the cells of the tooth bud, and more intensely expressed in mesenchymal cells, but it was not expressed in dental papilla (Fig. 1A).

Cap stage. On E17, the dental organ was formed by invagination of the tooth bud into mesenchymal cells that had formed the dental papilla by condensation. T $\beta 4$ was expressed strongly in the dental lamina, oral epithelium, and in a part of the cells in the outer and inner dental epithelia (Fig. 1B).

Early bell stage. On postnatal day 1 (PN1), the bell stage displayed a larger dental organ and dental papilla (pulp) compared to those of the cap stage. $\mathrm{T} \beta 4$ was expressed strongly in the cytoplasm of odontoblasts located on the outer layer of the pulp (Fig. 1C).

Advanced bell stage. The formation of dentin and enamel was observed in developing teeth on PN4. T $\beta 4$ was expressed in odontoblasts in a similar pattern as that on PN1, but expression was more intense in the apical area compared to PN1. Further, expression of $\mathrm{T} \beta 4$ was not detected in the negative control tissue (inset) (Fig. 1D).

Crown stage and functional stage. During the crown stage, the thickness of dentin increased, and $\mathrm{T} \beta 4$ expression increased in the odontoblast process and cytoplasm on PN7, PN10, and PN14 compared to PN4 (Fig. 1E-G). During the PN21 functional stage, $\mathrm{T} \beta 4$ was expressed in a similar pattern in the odontoblast process and cytoplasm as that in the crown stage (Fig. 1H).

Intensity of T $\beta 4$ expression in odontoblasts during tooth development. The expression intensity of $\mathrm{T} \beta 4$ protein was similar on PN1 and PN4. Moreover, it was 1.4-fold higher on PN7 and PN10 and 1.6-fold higher on PN14, compared to PN1 in odontoblast layers during tooth development. Further, the expression intensity of $\mathrm{T} \beta 4$ protein on PN21 was similar to that on PN14. Expression intensity of T $\beta 4$ protein was significantly high on PN7 compared to that on PN1 ( $p<0.05)$, and this aspect of PN7 was maintained up to PN21 (Fig. 1I).

Alizarin red $S$ staining during MDPC-23 and si-T $\beta 4 /$ MDPC-23 cell differentiation. The expression of $\mathrm{T} \beta 4$ in MDPC-23 cells was 23.4-fold higher on day 4 than that of the control, and it was decreased after day 7 during differentiation (Fig. 2A). The degree of mineralization was compared between MDPC-23 and si-T $34 /$ MDPC-23 cells after Alizarin red $\mathrm{S}$ staining. The intensity of staining gradually increased from day 4 to day 14 and decreased after day 21 during
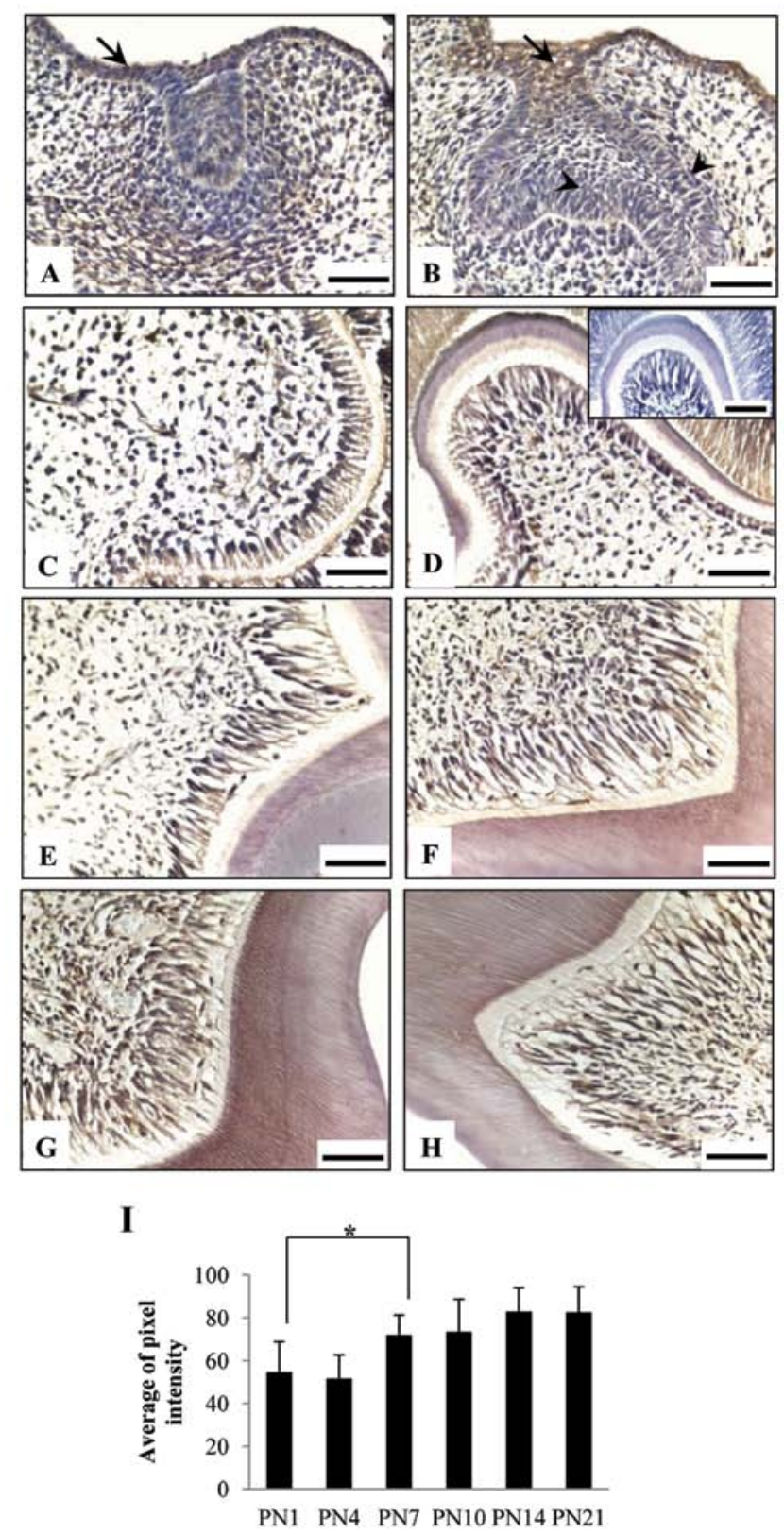

Figure 1. Expression of T $\beta 4$ protein in odontoblasts during tooth development (A) Bud stage: on embryonic day 15 (E15), T $\beta 4$ was expressed in the oral epithelium (arrow), inside cells of the tooth bud, and strongly expressed in mesenchymal cells. (B) Cap stage: on E17, T $\beta 4$ was expressed strongly in the dental lamina (arrow) and oral epithelium. Meanwhile, T $\beta 4$ was expressed weakly in the inner and outer epithelia of the dental organ (arrowhead). (C) Early bell stage: on postnatal day 1 (PN1), T $\beta 4$ was expressed intensively in the cytoplasm of odontoblasts. (D) Advanced bell stage: on PN4, T $\beta 4$ was expressed intensively in the apical area of cytoplasm. The negative control did not present immunohistochemical signals (inserted figure). Crown stage: the expression of T $\beta 4$ was increased on PN7 (E), PN10 (F), and PN14 (G) compared to the advanced bell stage in the odontoblast layer. $(\mathrm{H})$ Functional stage: on PN21, the expression and localization of T $\beta 4$ were similar to those during the crown stage. All scale bars indicate $20 \mu \mathrm{m}$. (I) The intensity of T $\beta 4$ expression was increased gradually from the early bell to the functional stage.

differentiation of MDPC-23 cells. However, the intensity of staining was significantly decreased in si-T $\beta 4 / \mathrm{MDPC}-23$ cells compared to that in MDPC-23 cells during differentiation (Fig. 2B). Further, the absorbance of Alizarin red S staining was not significantly different between MDPC-23 and si-T $\beta 4 /$ MDPC-23 cells on day 4, but it was 1.7 -fold lower on day 7 
A
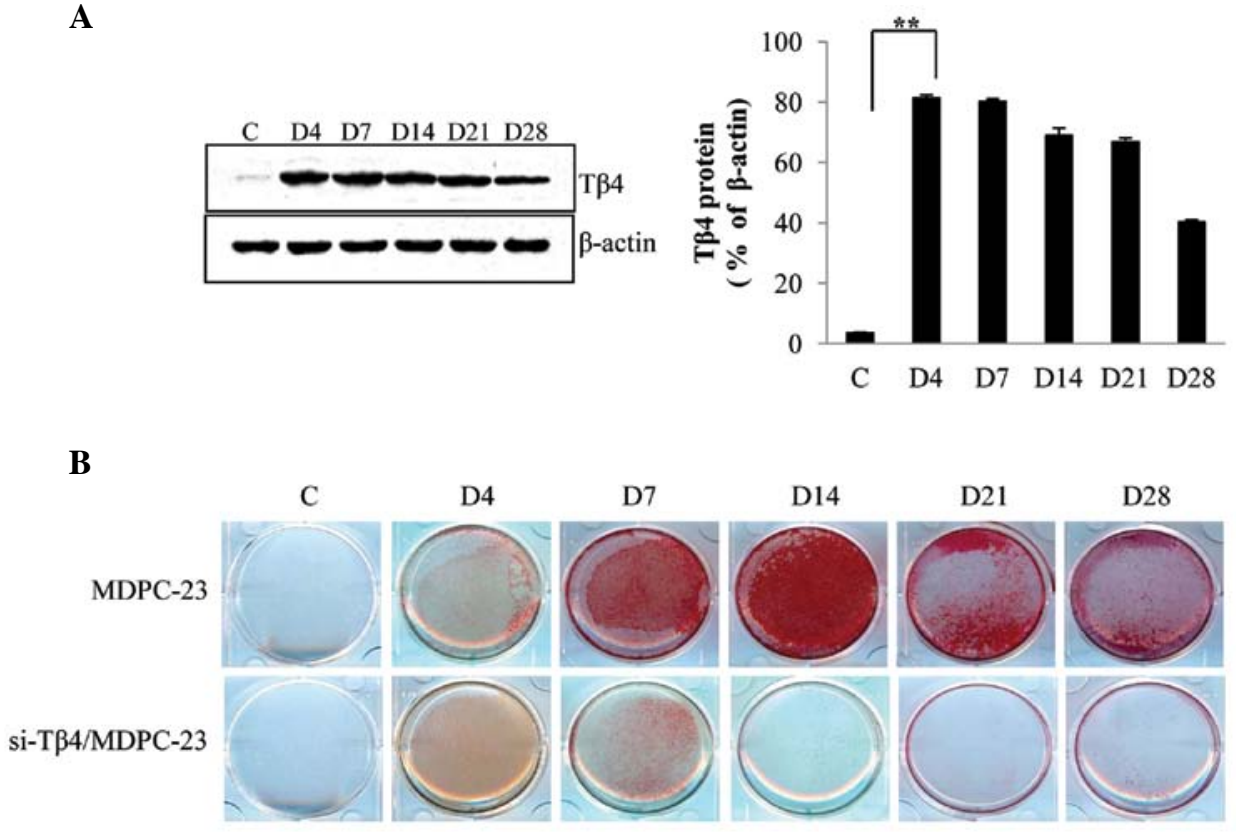

C

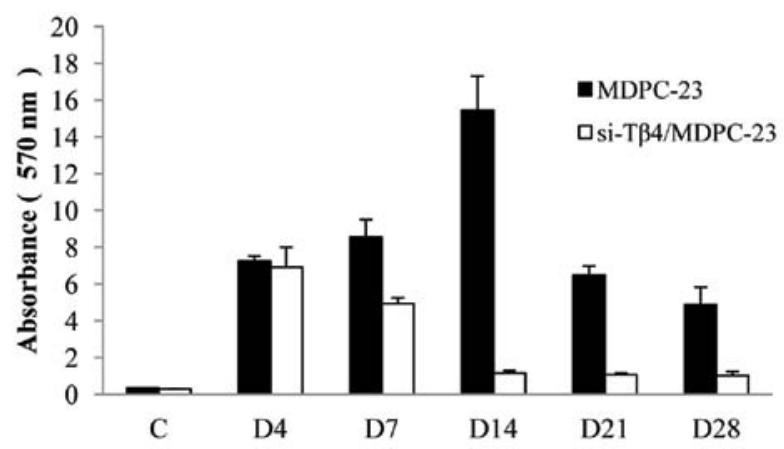

Figure 2. Mineralization in MDPC-23 and si-T $\beta 4 / \mathrm{MDPC}-23$ cells during differentiation. (A) T $\beta 4$ protein was expressed strongly on day 4 compared to the control and decreased gradually from day 7 to day 28 in MDPC- 23 cells. (B) Differentiation of si-T $\beta 4 / \mathrm{MDPC}-23$ cells showed significantly decreased numbers of nodules as indicated by intense Alizarin red S staining compared to MDPC-23 cells. (C) The absorbance of Alizarin red S staining was dramatically decreased in si-T/34/MDPC-23 cells compared to MDPC-23 cells during differentiation.

and 13.4-fold lower on day 14 in si-T $\beta 4 /$ MDPC-23 compared to MDPC-23 cells (Fig. 2C).

The $m R N A$ expression of genes related to differentiation and mineralization in MDPC-23 and si-T $\beta 4 / M D P C-23$ cells. After differentiation, T $\beta 4$ mRNA expression was 4.3 -fold higher on day 4 compared to that of control and gradually decreased from day 7 to day 28. DSPP mRNA expression was 14-fold higher on day 14 than that of the control and gradually increased until day 28. Expression of BSP and ON mRNA was 11.6-fold and 50 -fold higher, respectively, on day 7 compared to that of the control; however, it decreased from day 14 until no expression was observed from days 21 to 28 . OCN mRNA expression was 18.7 -fold higher on day 7 than the control and gradually decreased from day 14 to day 28 . Col type I mRNA expression was 2.2-fold higher on day 14 than that of the control and gradually decreased after day 14 (Fig. 3A and C). T $\beta 4$ and OCN mRNAs were barely expressed in si-T $\beta 4 /$ MDPC-23 cells. DSPP, BSP, ON, and Col type I mRNAs were not expressed in si-T $34 /$ MDPC-23 cells in contrast to MDPC-23 cells during differentiation (Fig. 3B and C).

\section{Discussion}

Tooth development is initiated by the formation of tooth bud protruding toward the mesenchyme through the proliferation of oral epithelial cells represented by the bud stage. In the cap stage, the tooth bud is transformed into the enamel organ through the continuous proliferation of oral epithelial cells, and dental papilla is formed by the increased density of surrounding mesenchymal cells (18). T $\beta 4$ mRNA and BrdU are strongly expressed in the same cells of the oral epithelium and tooth bud on E10.5 during the initial stage and on E13 and E14 during the bud stage $(16,19)$. Treatment of T 34 increases the proliferation of embryonic endothelial cells in mouse and oligodendrocytes in encephalomyelitis compared to a control group $(20,21)$. In this study, $\mathrm{T} \beta 4$ protein was strongly expressed in the oral epithelium and tooth bud during the bud stage. Further, T $\beta 4$ was strongly expressed in the dental lamina and oral epithelial cells during the cap stage. Therefore, $\mathrm{T} \beta 4$ may be involved in the proliferation of oral epithelial cells in the bud and cap stages in accordance with previous results. 
A

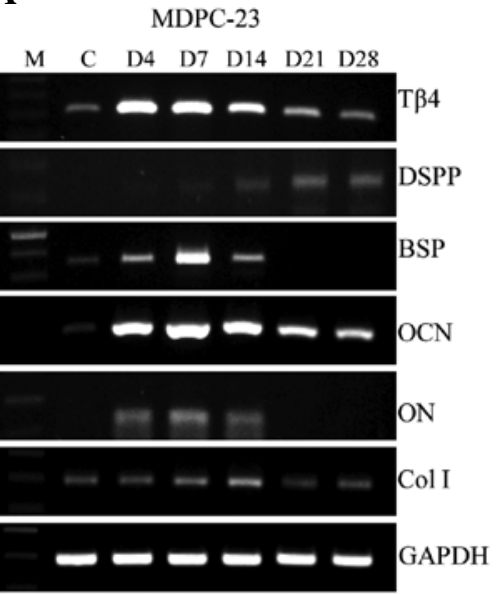

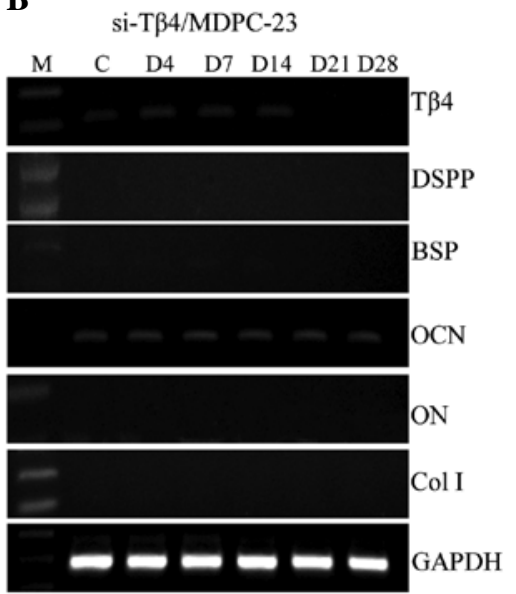

C
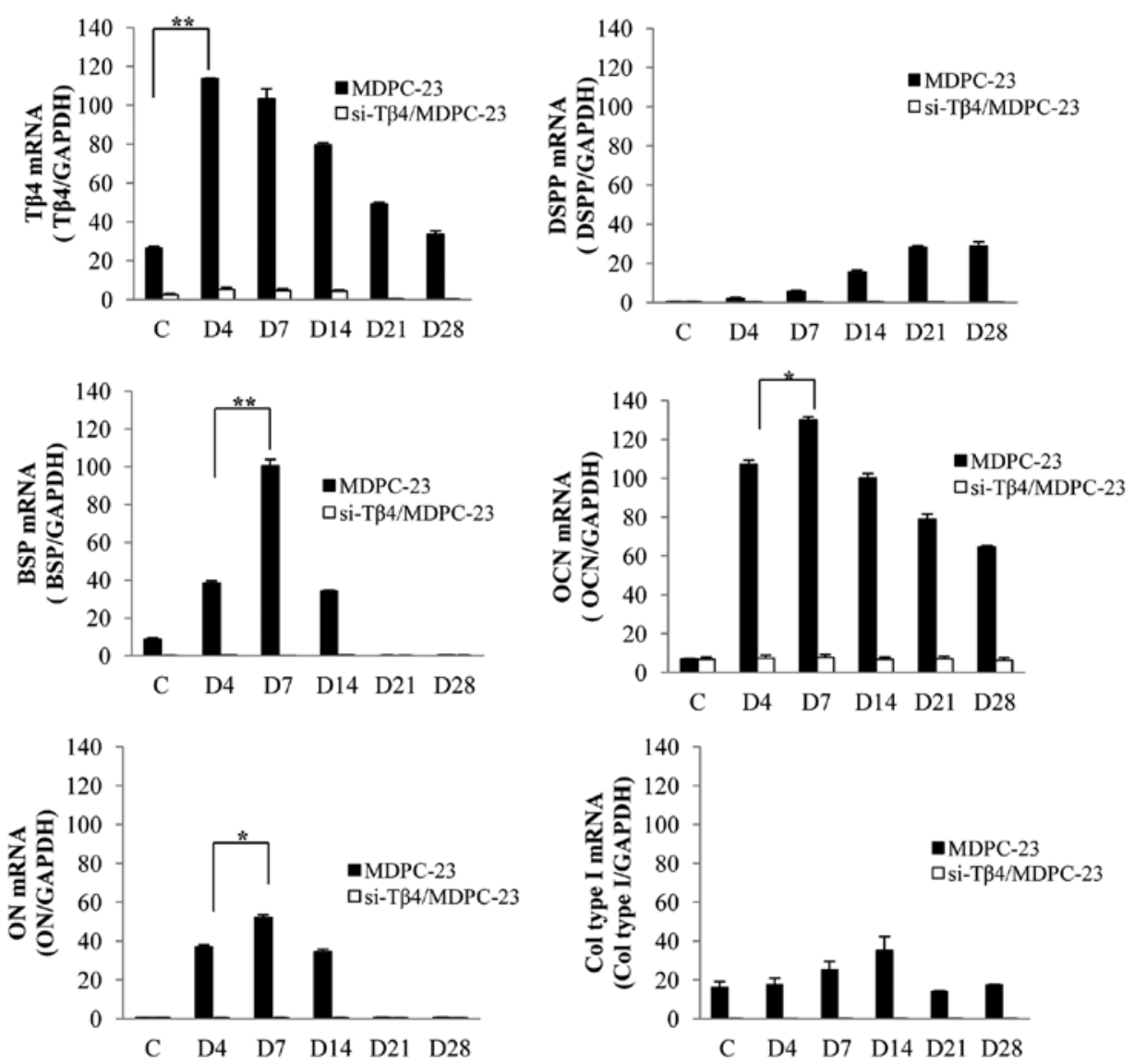

Figure 3. Expression of noncollagenous and collagenous genes in MDPC-23 and si-T $\beta 4 / M D P C-23$ cells during differentiation. (A) and (B) The expression of noncollagenous proteins (DSPP, BSP, OCN, and ON) and collagen type I mRNA was significantly decreased in si-T $\beta 4 / M D P C-23$ cells compared to MDPC-23 cells. (C) RT-PCR analysis shows that the intensity of mRNA expression was strongly inhibited by T $\beta 4$-siRNA during differentiation of MDPC-23 cells.

Odontoblasts are differentiated from dental papilla cells, which are formed by aggregation of mesenchymal cells during tooth development (22). The differentiation of odontoblasts is most active at the early bell stage, and odontoblasts initiate the formation of the dentin matrix at the advanced bell stage (23). Expression of $\mathrm{T} \beta 4$ has been identified in various mammalian cells. Overexpression of T $\beta 4$ leads to rapid vessel formation, whereas inhibition of $\mathrm{T} \beta 4$ expression decreases vessel formation in human umbilical vein endothelial cells (HUVECs) (24). Further, other studies have reported that treatment with $\mathrm{T} \beta 4$ promotes the terminal differentiation of keratinocytes due to the reduction of keratin 15 (K15) expression, which is known as the marker gene of undifferentiated hair follicle stem cells (10). In this study, expression of T $\beta 4$ mRNA and protein was strongly increased on day 4 and decreased from day 14 to day 28 during differentiation of MDPC-23 cells. Further, the mRNA expression of marker genes for odontoblasts, such as BSP, OCN, and ON, was increased similarly to the pattern of T $\beta 4$ mRNA expression on day 4 of differentiation. Further, the expression of $\mathrm{T} \beta 4$ protein, gradually increased from PN1 of the early bell stage to PN21 of the functional stage during tooth development. Therefore, $T \beta 4$ 
may be an important molecule affecting differentiation of odontoblasts.

The life span of odontoblasts is divided into the secretory, transitional, and aged phases according to their activity. Secretory odontoblasts are longer and larger in length and diameter compared to preodontoblasts, and they are characterized by the active synthesis of proteins due to distinct and well-developed rough endoplasmic reticulum, Golgi complex, secretory vesicles, and mitochondria. Reorganization of the cytoplasm occurs in transitional odontoblasts, and organelles including secretory vesicles are not observed in aged odontoblasts (25). The advanced bell stage is the initial stage of dentinogenesis, and secretory and aged odontoblasts are located in the cusp and cervical region during premolar development, respectively $(2,26)$.

Bone morphogenic protein-2 (BMP-2), BMP-4, BMP-7, and transforming growth factor- $\beta 1$ (TGF- $\beta 1$ ) stimulate mineralization according to morphological changes and differentiation of odontoblasts $(27,28)$. Treatment with TGF- $\beta 1$ and fibroblast growth factor-1 (FGF-1) or BMP-2 induces the differentiation of odontoblasts from dental papilla cells as well as synthesis of the dentin matrix $(29,27)$. The mRNA expression of TGF- $\beta 1$ and noncollagenous proteins such as ON and BSP is increased in secretory odontoblasts in the advanced bell stage during mouse tooth development (26). Further, expression of other noncollagenous proteins such as DPP, DSP, and DMP-1 is induced in odontoblast-like cells stimulated with differentiation medium (30). In this study, $\mathrm{T} \beta 4$ protein was expressed in the cytoplasm of odontoblasts located in the cusp on PN1 and PN4 during the bell stage. Expression of T $\beta 4$ in odontoblasts is localized to the cusp region, and the thickness of dentin was increased on PN7, PN10, and PN14 of the crown stage compared to the bell stage. On PN21 during the functional stage, the expression level of $\mathrm{T} \beta 4$ protein was similar to that during the crown stage in odontoblasts near the cusp.

Secretory vesicles, including proteins necessary for the formation of dentin, are released into the extracellular space after being transported from the Golgi complex to the odontoblasts processes by kinesin and ATP, which act as the motor protein and energy source, respectively (31). Treatment with T $\beta 4$ increases the release and influx of $\mathrm{Ca}^{2+}$ in human myeloid leukemic cells along with extocytosis of $\beta$-Hex, histamine, and tryptase from mast cells in a dose-dependent manner $(32,33)$. Further, T $\beta 4$ increases the exocytosis of cytolytic granules from natural killer cells (34). BMP-2 induces the expression of DSPP in odontoblasts during tooth development as well as the expression of heme oxygenase-1 (HO-1), a factor related to pulp cell differentiation, the expression of alkaline phosphatase (ALP), osteopontin (OPN), BSP, DMP-1, and DSPP mRNA $(35,36)$. Overexpression of Bcl-2 also decreases the expression of DMP-1, OC, DSPP, and Col type I mRNA (37). In the present study, the intensity of Alizarin red S staining and the expression levels of DSPP, BSP, ON, OCN, and Col type I were significantly decreased in si-T $\beta 4 / \mathrm{MDPC}-23$ cells compared to MDPC-23 cells. Therefore, $\mathrm{T} \beta 4$ may regulate the expression of genes related to mineralization during odontoblast differentiation during tooth development, similar to the effects of BMP-2, HO-1, and Bcl-2 reported in previous studies.

Taken together, our results suggest that $\mathrm{T} \beta 4$ may be involved in the proliferation of oral epithelial cells at the initial stage of tooth development and may regulate the expression and secretion of proteins during odontoblast differentiation.

\section{Acknowledgements}

This research was supported by the National Research Foundation of Korea (NRF) funded by the Ministry of Education, Science and Technology (R13-2008-010-00000-0).

\section{References}

1. Nanci A: Development of the tooth and its supporting tissues. In: Ten Cate's Oral Histology: Development, Structure, and Function. Dolan JJ and Pendill J (eds). Elsevier Inc., St. Louis, pp89-98, 2008.

2. Lisi S, Peterková R, Peterka M, Vonesch JL, Ruch JV and Lesot H: Tooth morphogenesis and pattern of odontoblast differentiation. Connect Tissue Res 44: 167-170, 2003.

3. Butler WT: Dentin matrix proteins. Eur J Oral Sci 1: 204-210, 1998.

4. Arana-Chavez VE and Massa LF: Odontoblasts: the cells forming and maintaining dentine. Int J Biochem Cell Biol 36: 1367-1373, 2004

5. Sasaki T and Garant PR: Structure and organization of odontoblasts. Anat Rec 245: 235-249, 1996.

6. Safer D, Sosnick TR and Elzinga M: Thymosin beta 4 binds actin in an extended conformation and contacts both the barbed and pointed ends. Biochemistry 36: 5806-5816, 1997.

7. Goldstein AL, Hannappel E and Kleinman HK: Thymosin beta4: actin-sequestering protein moonlights to repair injured tissues. Trends Mol Med 11: 421-429, 2005.

8. Li X, Zheng L, Peng F, Qi C, Zhang X, Zhou A, Liu Z and Wu S: Recombinant thymosin beta 4 can promote full-thickness cutaneous wound healing. Protein Expr Purif 56: 229-236, 2007.

9. Sosne G, Siddiqi A and Kurpakus-Wheater M: Thymosin-beta4 inhibits corneal epithelial cell apoptosis after ethanol exposure in vitro. Invest Ophthalmol Vis Sci 45: 1095-1100, 2004.

10. Philp D, St-Surin S, Cha HJ, Moon HS, Kleinman HK and Elkin M: Thymosin beta 4 induces hair growth via stem cell migration and differentiation. Ann N Y Acad Sci 1112: 95-103, 2007.

11. Grant DS, Rose W, Yaen C, Goldstein A, Martinez J and Kleinman H: Thymosin $\beta 4$ enhances endothelial cell differentiation and angiogenesis. Angiogenesis 3: 125-135, 1999.

12. Gómez-Márquez J, Franco del Amo F, Carpintero P and Anadón R: High levels of mouse thymosin b4 mRNA in differentiating P19 embryonic cells and during development of cardiovascular tissues. Biochim Biophys Acta 1306: 187-193, 1996.

13. Anadón R, Moldes IR, Carpintero P, Evangelatos G, Livianou E, Leondiadis L, Quintela I, Cerviño MC and Gómez-Márquez J: Differential expression of thymosins $\beta 4$ and $\beta 10$ during rat cerebellum postnatal development. Brain Res 894: 255-265, 2001.

14. Yamaza H, Matsuo K, Kiyoshima T, Shigemura N, Kobayashi I, Wada H, Akamine A and Sakai H: Detection of differentially expressed genes in the early developmental stages of the mouse mandible. Int J Dev Biol 45: 675-680, 2001.

15. Clark EA, Golub TR, Lander ES and Hynes RO: Genomic analysis of metastasis reveals an essential role for RhoC. Nature 406: 532-535, 2000.

16. Akhter M, Kobayashi I, Kiyoshima T, Matsuo K, Yamaza H, Wada H, Honda JY, Ming X and Sakai H: Possible functional involvement of thymosin beta 4 in developing tooth germ of mouse lower first molar. Histochem Cell Biol 124: 207-213, 2005.

17. Choi BD, Jeong SJ, Wang G, Kim HJ, Kim BO, Hwang HK, Lim DS, Kim SH and Jeong MJ: Temporal induction of secretory leukocyte protease inhibitor (SLPI) in odontoblasts by lipopolysaccharide and wound infection. J Endod 35: 997-1002, 2009.

18. Ruch JV: Tooth morphogenesis and differentiation. In: Dentin and Dentinogenesis. Linde A (ed). CRC Press, Boca Raton, pp447-479, 1984.

19. Shigemura N, Kiyoshima T, Kobayashi I, Matsuo K, Yamaza H, Akamine A and Sakai H: The distribution of BrdU- and TUNELpositive cells during odontogenesis in mouse lower first molars. Histochem J 31: 367-377, 1999. 
20. Bock-Marquette I, Shrivastava S, Pipes GC, Thatcher JE, Blystone A, Shelton JM, Galindo CL, Melegh B, Srivastava D, Olson EN and DiMaio JM: Thymosin beta4 mediated PKC activation is essential to initiate the embryonic coronary developmental program and epicardial progenitor cell activation in adult mice in vivo. J Mol Cell Cardiol 46: 728-738, 2009.

21. Zhang J, Zhang ZG, Morris D, Li Y, Roberts C, Elias SB and Chopp M: Neurological functional recovery after thymosin beta4 treatment in mice with experimental auto encephalomyelitis. Neuroscience 164: 1887-1893, 2009.

22. Theslef I and Sharpe P: Signalling networks regulating dental development. Mech Dev 67: 111-123, 1997.

23. Butler WT: Dentin matrix proteins and dentinogenesis. Connect Tissue Res 33: 56-65, 1995.

24. Grant DS, Kinsella JL, Kibbey MC, LaFlamme S, Burbelo PD, Goldstein AL and Kleinman HK: Matrigel induces thymosin beta 4 gene in differentiating endothelial cells. J Cell Sci 108: 3685-3694, 1995.

25. Couve E: Ultrastructural changes during the life cycle of human odontoblasts. Arch Oral Biol 31: 643-651, 1986.

26. Bègue-Kirn C, Smith AJ, Loriot M, Kupferle C, Ruch JV and Lesot H: Comparative analysis of TGF beta, BMPs, IGF1, msxs, fibronectin, osteonectin and bone sialoprotein gene expression during normal and in vitro-induced odontoblast differentiation. Int J Dev Biol 38: 405-420, 1994.

27. Bègue-Kirn C, Smith AJ, Ruch JV, Wozney JM, Purchio A Hartmann D and Lesot $\mathrm{H}$ : Effects of dentin proteins, transforming growth factor beta 1 (TGF beta 1) and bone morphogenetic protein 2 (BMP2) on the differentiation of odontoblast in vitro. Int J Dev Biol 36: 491-503, 1992.

28. Nakashima M, Nagasawa H, Yamada $\mathrm{Y}$ and Reddi AH: Regulatory role of transforming growth factor-beta, bone morphogenetic protein-2, and protein-4 on gene expression of extracellular matrix proteins and differentiation of dental pulp cells. Dev Biol 162: 18-28, 1994.
29. Unda FJ, Martin A, Hilario E, Begue-Kirn C, Ruch JV and Arechaga J: Dissection of the odontoblast differentiation process in vitro by a combination of FGF1, FGF2, and TGFbetal. Dev Dyn 218: 480-489, 2000.

30. Hanks CT, Fang D, Sun Z, Edwards CA and Butler WT: Dentinspecific proteins in MDPC-23 cell line. Eur J Oral Sci 106: 260-266, 1998.

31. Garant PR: The organization of microtubules within rat odontoblastic processes revealed by perfusion fixation with glutaraldehyde. Arch Oral Biol 17: 1047-1058, 1972.

32. Huang WQ, Wang BH and Wang QR: Thymosin beta4 and AcSDKP inhibit the proliferation of HL-60 cells and induce their differentiation and apoptosis. Cell Biol Int 30: 514-520, 2006.

33. Wyczółkowska J, Walczak-Drzewiecka A, Wagner W and Dastych J: Thymosin beta4 and thymosin beta4-derived peptides induce mast cell exocytosis. Peptides 28: 752-759, 2007.

34. Lee HR, Yoon SY, Kang HB, Park S, Kim KE, Cho YH, Kim S, Kim CW, Cho BJ, Lee WJ, Bang SI, Park H and Cho D: Thymosin beta 4 enhances NK cell cytotoxicity mediated by ICAM-1. Immunol Lett 123: 72-76, 2009.

35. Chen S, Gluhak-Heinrich J, Martinez M, Li T, Wu Y, Chuang HH, Chen L, Dong J, Gay I and MacDougall M: Bone morphogenetic protein 2 mediates dentin sialophosphoprotein expression and odontoblast differentiation via NF-Y signaling. J Biol Chem 283: 19359-19370, 2008.

36. Kim SJ, Min KS, Ryu HW, Lee HJ and Kim EC: The role of heme oxygenase- 1 in the proliferation and odontoblastic differentiation of human dental pulp cells. J Endod 36: 1326-1331, 2010.

37. Zhang W, Ju J and Gronowicz G: odontoblast-targeted Bcl-2 overexpression impairs dentin formation. J Cell Biochem 111: 425-432, 2010. 